\title{
Patient and health service delay in pulmonary tuberculosis patients attending a referral hospital: a cross-sectional study Mpungu S Kiwuwa*1, Karamagi Charles ${ }^{\dagger 1}$ and Mayanja Kizza Harriet ${ }^{\dagger 2}$
}

Address: ${ }^{1}$ Clinical Epidemiology Unit, Makerere University, Faculty of Medicine, P.O Box 7072, Kampala, Uganda and ${ }^{2}$ Department of Medicine, Makerere University, Faculty of Medicine, P.O Box 7072, Kampala, Uganda

Email: Mpungu S Kiwuwa* - skiwuwa@med.mak.ac.ug; Karamagi Charles - ckaramagi2000@yahoo.com; Mayanja Kizza Harriet - hmk@cwru.or.ug

* Corresponding author †Equal contributors

Published: 24 November 2005

BMC Public Health 2005, 5:122 doi:10.1 |86/147|-2458-5-122
Received: 10 February 2005

Accepted: 24 November 2005

This article is available from: http://www.biomedcentral.com/I47/-2458/5//22

(c) 2005 Kiwuwa et al; licensee BioMed Central Ltd.

This is an Open Access article distributed under the terms of the Creative Commons Attribution License (http://creativecommons.org/licenses/by/2.0), which permits unrestricted use, distribution, and reproduction in any medium, provided the original work is properly cited.

\begin{abstract}
Background: Delays in diagnosis and initiation of effective treatment increase morbidity and mortality from tuberculosis as well as the risk of transmission in the community. The aim of this study was to determine the time taken for patients later confirmed as having TB to present with symptoms to the first health provider (patient delay) and the time taken between the first health care visit and initiation of tuberculosis treatment (health service delay). Factors relating to these 'delays' were analyzed.
\end{abstract}

Methods: A cross-sectional survey, of 23I newly diagnosed smear-positive tuberculosis patients was conducted in Mulago National referral Hospital Kampala, from January to May 2002. Socio-demographic, lifestyle and health seeking factors were evaluated for their association with patient delay (>2 weeks) and health service delay (>4 weeks), using odds ratios with $95 \%$ confidence intervals $(\mathrm{Cl})$ including multivariate logistic regression.

Results: The median total delay to treatment initiation was 12 weeks. Patients often presented to drug shops or pharmacies $(39.4 \%$ ) and private clinics $(36.8 \%)$ more commonly than government health units (I4\%) as initial contacts. Several independent predictors of 'patient delay' were identified: being hospitalized (odds ratio [OR] $=0.32$; $95 \% \mathrm{Cl}$ : $0.12-0.80$ ), daily alcohol consumption (OR $=3.7$; $\mathrm{Cl}$ : I.579.76), subsistence farming ( $O R=4.70 ; \mathrm{Cl}:$ I.67-13.22), and perception of smoking as a cause of TB (OR $=5.54 ; \mathrm{Cl}: 2.26-13.58)$. Independent predictors of 'health service delay' were: $>2$ health seeking encounters per month $(\mathrm{OR}=2.74 ; \mathrm{Cl}: \mathrm{I} .10-6.83)$, and medical expenditure on TB related symptoms $>29$ US dollars (OR = 3.88; $\mathrm{Cl}$ : I.19-12.62). Perceived TB stigma and education status was not associated with either form of delay.

Conclusion: Delay in diagnosis of TB is prolonged at the referral centre with a significant proportion of Health service delay. More specific and effective health education of the general public on tuberculosis and seeking of appropriate medical consultation is likely to improve case detection. Certain specific groups require further attention. Alcoholics and subsistence farmers should be targeted to improve accessibility to TB treatment. Continuing medical education about TB management procedures for health providers and improvement in the capacity of TB control services should be undertaken. 


\section{Background}

Uganda is one of the global TB high burden countries ranked $20^{\text {th }}$ in the world with an estimated incidence rate of tuberculosis in 2001 of 324 cases per 100,000 and a notification rate of 171 per 100,000 of the population. The estimated proportion of tuberculosis cases that were HIV positive was 35\% in 2001. The number of reported TB cases is increasing with 19,016 cases registered in 1991 and 41,831 in 2001[1]. This increase is possibly due to population growth, improvement in case finding or a true increase, as sentinel sero-prevalence surveys in Ugandan hospitals had shown that $45 \%$ to $65 \%$ of newly diagnosed TB patients were HIV positive[2]. The detection of new sputum smear positive cases was $52 \%$, which is far below the (WHO) case detection target of 70\%[3].

In Mulago National Referral TB treatment center located in Kampala, the capital city of Uganda, clinic records show that the majority of tuberculosis patients have had symptoms for two or more months before seeking TB treatment. Delays in diagnosis and initiation of effective treatment increase morbidity and mortality from tuberculosis as well as the risk of transmission in the community. The stigma attached to TB disease may hinder access to timely health care[4].

In patients with $\mathrm{TB}$, the low detection and cure rates may be attributed to limited information about factors contributing to delayed diagnosis in Uganda. Recent work in Mukono [5], a mainly rural district revealed that there is considerable delay in diagnosis of TB. However factors contributing to delay in diagnosis and treatment are likely to vary depending on the populations in their local settings. The aim of this study was to determine the time interval between symptom onset and initiation of TB treatment [6,7] and analyze the determinants of this interval. From this study, it was determined which factors serve as barriers or facilitators for seeking treatment early, how these factors are interrelated and which ones are liable to behavioral change or social encouragement by health education and health promotion.

\section{Methods}

\section{Ethical considerations}

Institutional consent was obtained from the Faculty Research and Ethics Committee of the Medical School (institutional ethical board for the medical school).

\section{Study setting}

The study was carried out at the National Tuberculosis and Leprosy control program (NTLP) center of Mulago hospital situated in the city centre. This treatment center is the principal facility providing in-patient and outpatient TB care in Kampala district. The TB center which is one of Mulago hospital's various departments has an inpatient bed capacity of about 100 beds. The hospital provides services to Kampala's population of about 1,208,544 (Uganda population census 2001) and surrounding districts plus upcountry referrals. TB patients are usually referred to the center from other hospitals, medical centers and private practitioners in and outside Kampala. Most health care units are strategically located within the city, and the transport system has good coverage. The TB control program initiated decentralization of TB management services to the district and sub-district levels, in 1997. The total number of new TB patients including children registered at the center in 2001 was about 4000.

\section{Study participant selection}

We performed a cross-sectional study during a fourmonth period from January to May 2002 during which a total of 1,382 TB patients were registered at the treatment center. Eligible participants were patients presenting to the center aged 18 years or older, with newly diagnosed sputum smear positive pulmonary tuberculosis. Consenting eligible patients were consecutively enrolled and interviewed by one of three trained research assistants including the principal author, within two days of the pulmonary tuberculosis diagnosis, using a semi-structured questionnaire.

For hospitalized patients, the TB register at the treatment centre was used to identify eligible patients. Such patients were then located on the ward for consent to participate in the study. Most interviews were conducted in the main local language of the area (Luganda), or in English. Retreatment patients and those with sputum negative disease were excluded from the study. The questionnaire was pre-tested among TB patients prior to the start of study, with modifications incorporated in the final version. The questionnaire collected information on the following attributes including: (a) Demographic and socio-economic variables: age, sex, occupation, education level, and family size; (b) Physical factors: symptoms and their duration, sputum results and chest radiographic findings); (c) Psychological factors: patient beliefs, perceptions, attitudes and knowledge about tuberculosis; (d) Institutional or health service factors: distance to health facilities, costs of travel and medical expenditure on treatment of TB related symptoms. Each interview schedule lasted approximately 40 minutes per participant and allowed for careful probing of responses to minimize recall bias. Other data sources were case notes and referral letters. A chest physician interpreted chest radiographic findings and regular supervision of the interviewers was conducted throughout the study period.

Participants were asked to estimate the time in months or weeks they had been experiencing the major presenting symptoms - evening fevers, night sweats, chest pain, diffi- 
Table I: Socio-demographic characteristics and distribution of the various time delays among the participants*

\begin{tabular}{|c|c|c|c|}
\hline \multicolumn{2}{|l|}{ Characteristic } & \multicolumn{2}{|l|}{$\begin{array}{c}\text { Patients, No. } \\
\text { (\%) }\end{array}$} \\
\hline Age, mean (SD), y & & $30.7(9.4)$ & \\
\hline \multicolumn{4}{|l|}{ Sex } \\
\hline Male & & $132(57.1)$ & \\
\hline Female & & $99(42.9)$ & \\
\hline \multicolumn{4}{|l|}{ Hospital admission status } \\
\hline Hospitalised & & $72(25.5)$ & \\
\hline Outpatients & & $159(74.5)$ & \\
\hline \multicolumn{4}{|c|}{ Highest education level attained } \\
\hline None & & $21(9.1)$ & \\
\hline Primary school & & $118(51.1)$ & \\
\hline Secondary & & $58(25.1)$ & \\
\hline Post-secondary & & $13(5.6)$ & \\
\hline Tertiary & & $21(9.1)$ & \\
\hline \multicolumn{4}{|c|}{ No. of persons in Household } \\
\hline (I) & & $24(10.4)$ & \\
\hline$(>1)$ & & $207(89.6)$ & \\
\hline \multicolumn{4}{|c|}{ Weekly Alcohol consumption } \\
\hline Daily & & $35(15.2)$ & \\
\hline Sometimes & & $47(20.3)$ & \\
\hline Rarely & & $26(11.3)$ & \\
\hline Never & & $123(53.2)$ & \\
\hline \multicolumn{4}{|l|}{ Main Occupation } \\
\hline Subsistence farming & & $28(12.1)$ & \\
\hline Unskilled workers & & $115(49.8)$ & \\
\hline Skilled workers & & $56(24.2)$ & \\
\hline Students & & $20(8.7)$ & \\
\hline Unemployed & & $12(5.2)$ & \\
\hline \multicolumn{4}{|c|}{ Medical expenditure on TB related symptoms, US $\$$} \\
\hline $0-29$ & & $123(53.2)$ & \\
\hline$>29$ & & $108(46.8)$ & \\
\hline \multicolumn{4}{|c|}{ Distance from home to treatment centre, $\mathrm{km}$} \\
\hline$<25$ & & $197(85.3)$ & \\
\hline$>25$ & & $34(14.7)$ & \\
\hline \multicolumn{4}{|c|}{ Distribution of the time delays } \\
\hline & $\begin{array}{l}\text { Patient } \\
\text { delay }\end{array}$ & $\begin{array}{l}\text { Health service } \\
\text { delay }\end{array}$ & $\begin{array}{l}\text { Total } \\
\text { delay }\end{array}$ \\
\hline Median, wk & 1.0 & 9.0 & 12.0 \\
\hline Interquartile Range, wk & $0.9-4.0$ & $5.3-15.3$ & $8.0-20.0$ \\
\hline Delay $>2 \mathrm{wk}$ & $70(30.3)$ & $207(89.6)$ & $231(100)$ \\
\hline Delay $>4$ wk & $40(14.7)$ & $188(81.4)$ & $210(90.9)$ \\
\hline
\end{tabular}

*Values are number $\%$ unless otherwise indicated

culty in breathing, weight loss, loss of appetite or generalized weakness along with the cough episode leading to initiation of tuberculosis treatment (total delay). Patient delay was the estimated time interval between symptom onset and the first medical consultation and the time taken from then until the diagnosis was confirmed and treatment started was considered as health service delay[6,7]. In our study a health provider was defined as any person consulted by the patient about his/her sick- ness who prescribed any form of medication. These included dispensers, pharmacists, medical staff and herbalists or traditional healers. The estimated sample size of 231 patients was obtained assuming, from prior local studies that $80 \%$ would have a total delay of more than 4 weeks [8]. A total delay of more than four weeks was considered, as national guidelines suggest that patients coughing for more than 3 weeks should be investigated further. Limitations of our study include imprecise estimates of delay due to recall bias or in some cases, lack of case notes and referral letters to verify the accuracy of information given, and the single center studied.

\section{Data management and analysis}

In order to ensure data quality, the data was double entered into a computer, and the two copies of the data verified. Delay in weeks was presented as medians and proportions. Patient delay (classified as presentation after 2 weeks of the onset of symptoms) and health service delay (when patient was delayed $>4$ weeks between initial contact with health provider and treatment onset) were compared for different sub-groups using odds ratios and $95 \%$ CI. To identify factors independently associated with patient delay and health service delay, a multivariate logistic regression analysis with delay time dichotomized as described above was performed. When appropriate, non-parametric tests (Chi-square, Mann-Whitney and Kruskal-Wallis tests) were used where assumptions of normality were unmet. Statistical significance was taken as $\mathrm{P}$ $<0.05$.

\section{Results}

\section{Socio-demographic characteristics of the participants}

Two hundred thirty one eligible adult newly diagnosed smear positive TB patients were recruited into the study. The mean age was $30.7\{$ Standard deviation $(\mathrm{SD})=9.4\}$, with a median age of 30 years. The mean age of the males $32.2(\mathrm{SD}=9.2)$ years and females $28.7(\mathrm{SD}=9.2)$ years were significantly different $(\mathrm{p}<0.05)$. Seventy-two $(25.5 \%)$, were hospitalized at the time of diagnosis. The mean family size was $4(\mathrm{SD}=2.4)$ with a range of $(1-11)$. One hundred and thirty-nine had at most post-primary education regardless of gender. Occupation wise 28 $(12.1 \%)$ were subsistence farmers, $56(24.2 \%)$ skilled workers and $115(49.8 \%)$ unskilled workers including traders and housewives. Of those who did not earn any income, $15(11.4 \%)$ were more likely to be male compared to $36(36.4 \%)$ of the females $(\mathrm{P}<0.001)$. The average medical expenditure on treatment of TB related symptoms was 30 US dollars range (0-412) (Table 1).

\section{Clinical characteristics of the participants at presentation} The mean performance status (Karnofsky score) which is a measure of the degree of debility, of the respondents was $80(S D=10)$. Of our participants, symptoms experienced 
Table 2: First health facility visited by the participants for their illness and corresponding median time delays in weeks

\begin{tabular}{lccccc}
\hline First health facility visited & Number & $\%$ & Patient delay & Health service delay & Total delay \\
\hline Pharmacy/Drug shop & 91 & 39.4 & 1.0 & 10.6 & 8.4 \\
Private clinic & 85 & 36.8 & 1.0 & 9.9 & 12.0 \\
Traditional healer & 21 & 9.1 & 3.0 & 4.0 & 12.0 \\
Government hospital & 13 & 5.6 & 3.0 & 0.0 & 12.0 \\
Health center & 10 & 4.3 & 10.0 & 22.0 & 10.0 \\
NTLP center & 9 & 3.9 & & & \\
Non Governmental hospital* & 2 & 0.9 & & & \\
\hline
\end{tabular}

*Delay times not stated because cases were very few.

included; hemoptysis 63 (27.3\%), fever $78.4 \%$, chest pain $68.4 \%$, anorexia, $57.6 \%$, exertional dyspnoea $74 \%$, fatigue $77.9 \%$, and cervical lymphadenopathy $6.5 \%$.

Fourteen $(25 \%)$ of the hospitalised patients had $\leq 3$ affected lung zones compared to $22(13 \%)$ of the outpatients $(\mathrm{OR}=2.20$; CI: 1.05-4.72). Participants who ever had hemoptysis before diagnosis had a longer delay to initiation of TB treatment (Mann-Whitney test P-value = 0.019). Disease severity as measured by AFB (Alcohol Acid Fast Bacilli) sputum smear grades, was also associated with the duration of delay to treatment. (KruskallWalis test $\mathrm{P}<0.001$ ). It was also observed that presence of cavitary disease was associated with prolonged delay to initiation of treatment (Man-Whitney test $\mathrm{P}<0.001$ ).

HIV sero-status information assessed by self-report was only available in $56(24 \%)$ of the respondents, in which an association with delay could not be established. However self reported HIV positive sero-status results were more common among hospitalised participants $18(90 \%)$ compared to $10(27.8 \%)$ in the out-patients $(\mathrm{OR}=23$; CI: 4.57-119.77).

Self reported HIV positive patients were more likely to be female $20(69.0 \%)$ vs. male $8(29.6 \%),(\mathrm{OR}=5.30$; CI 1.69-16.40); and were un-likely to have cavitary disease $24(85.7 \%)$ vs. $13(46.4 \%)$ of the self reported HIV seronegatives. $(\mathrm{OR}=6.92$; CI: 1.90-25.23).

\section{Distribution of the various time delays}

The time delays experienced by the patients are described in Table 1 as well. Health service delay was the most frequent type of delay observed and the greatest contributor to total delay. The total delay to treatment was more than one month in $210(90.9 \%)$ and exceeded 2 months in $65.8 \%$ of the cases.

\section{Place of first presentation}

Table 2 shows the first health facility visited by the participants for their illness and the corresponding time delays. Seventy six percent of the patients had first presented to a private clinic or pharmacy/drug shop. Health service delay was longest (13.7 weeks) for those who first approached government health centres for their sickness. Of those who initially presented to government hospitals for treatment, $46.2 \%$ were investigated for $\mathrm{TB}$ using sputum microscopy; and $69.2 \%$ of them, were unlikely to change to another health facility. The prevalence of self-referral to the NTLP centre was 33\% and family members were seen to be an important source of influence in seeking treatment in $53 \%$ of the cases.

\section{Respondents' awareness of TB symptoms and perceived causes}

The most frequently mentioned TB symptom was persistent cough $(40.7 \%)$ and wasting $(25.1 \%)$ and fever $(9.5 \%)$. One hundred and fifteen (50\%) patients were not aware of any possible causes of $\mathrm{TB}$, and only $7.4 \%$ mentioned that germs cause TB. As noted, there was a low level of awareness of TB symptoms and it's causes in this study population. About $56 \%$ of the respondents acknowledged that TB patients are stigmatised in their communities. For instance, $40 \%$ of participants would not want to be near a $\mathrm{TB}$ case.

\section{Factors associated with patient delay}

Table 3 presents un-adjusted and adjusted odds ratios for patient delay ( $>2$ weeks) for a number of socio-demographic, lifestyle and health seeking factors. Of all the factors investigated, we found that hospitalized patients had a shorter delay to seeking treatment compared to outpatients ( $\mathrm{OR}=0.38,95 \% \mathrm{CI}, 0.18-0.81)$. Notably subsistence farmers delayed longer seeking help for treatment compared to the rest of the respondents $(\mathrm{OR}=4.70$; $\mathrm{CI}$ : 1.67-13.22); and were more likely not to have had postprimary education $27(96.4 \%)$, compared to the other participants 112 (55.2\%), (OR = 21.94; CI: 2.93-164.55). 
Table 3: Relationship between socio-demographic, lifestyle and health seeking factors to Patient delay. Both unadjusted and adjusted odds ratios are shown $(n=231)$

\begin{tabular}{|c|c|c|c|c|c|}
\hline Variable & $\mathbf{n}$ & $\begin{array}{c}\% \text { Patient delay } \\
>2 \text { weeks }\end{array}$ & $\begin{array}{c}\text { Unadjusted odds ratio } \\
(95 \% \mathrm{CI})\end{array}$ & $\mathbf{n}^{*}$ & $\begin{array}{c}\text { Adjusted odds ratio } \dagger \\
(95 \% \mathrm{CI})\end{array}$ \\
\hline Age $18-40, y$ & 205 & 30.2 & $0.98(0.40-2.40)$ & & NA \\
\hline Male & 132 & 35.6 & $1.83(1.02-3.29)$ & & NA \\
\hline Hospitalised & 59 & 16.9 & $0.38(0.18-0.81)$ & 56 & $0.32(0.12-0.80) \ddagger$ \\
\hline Marital status separated/single & 125 & 30.4 & I.0I (0.58-I.77) & & NA \\
\hline Post primary education Level & 92 & 25.0 & $0.65(0.36-1.18)$ & & NA \\
\hline >I Household persons & 207 & 28.5 & $0.47(0.20-1.11)$ & & NA \\
\hline Daily Alcohol consumption & 38 & 51.5 & $2.93(1.41-6.11)$ & 34 & $3.70(1.57-9.76) \ddagger$ \\
\hline Subsistence farming & 28 & 46.4 & $2.22(1.02-5.00)$ & 26 & $4.70(1.67-13.22) \ddagger$ \\
\hline Perceived smoking as cause of TB & 34 & 55.9 & $3.63(1.72-7.66)$ & 34 & $5.54(2.26-13.58) \ddagger$ \\
\hline$>2$ Health seeking encounters per month & 76 & 13.2 & $0.24(0.12-0.50)$ & 72 & $0.15(0.06-0.36) \ddagger$ \\
\hline
\end{tabular}

*Number included in forward stepwise logistic regression method.

†Odds ratios for the variables appearing at the final step of forward stepwise selection.

$\ddagger \mathrm{P}<0.05 ; \mathrm{Cl}$ indicates confidence interval; NA not applicable.

Other independent predictors of patient delay included: daily alcohol consumption ( $0 \mathrm{R}=3.70$; CI: $1.57-9.67)$ and misperceptions that TB is caused by smoking $(\mathrm{OR}=$ 5.54; CI: 2.26-13.58). Compared with males, females had a shorter delay seeking help for symptoms, although this finding did not reach statistical significance. Severity of initial symptoms and age had no effect on patient delay.

\section{Factors associated with health Service Delay}

The median health service delay was 9 weeks range $(0.1-$ 135.6). Only fifty-eight (36\%) of the patients were diagnosed and initiated on treatment within one month following initial contact with a health provider. Of the factors investigated, these were the three independent predictors of health service delay $>4$ weeks, after adjusting for other variables (Table 4) namely: medical expenditure on treatment of TB related symptoms $>29$ US dollars, (OR = $3.88),>2$ multiple health seeking encounters per month $(\mathrm{OR}=2.74)$ and residing alone $(\mathrm{OR}=0.31)$. Presence of hemoptysis at onset was associated with health service delay although this aspect did not reach statistical significance.

\section{Discussion \\ Delay in diagnosis and initiation of TB treatment}

This study from Kampala Uganda highlights the prolonged delay from onset of patients' symptoms until initiation of TB treatment at Mulago hospital. Health service delay $(74 \%)$ represented the main component of the overall total delay, reflecting an inadequacy of the clinical services to diagnose TB among symptomatic individuals. The median total delay to treatment of 12 weeks observed in this study is similar to that seen in other studies $[6,9,10]$. In Uganda [5], Oola (2001) found a median total delay of
17 weeks among both smear positive and smear negative TB patients.

Seventy percent of the respondents reported visiting a health provider within 2 weeks of onset of signs and symptoms. This short patient delay could reflect good awareness of health problems and easy access to health care in the study population. However $21(9 \%)$ of patients sought the initial treatment 2 months after symptom onset. Often misinterpretation of initial symptoms results in actions (patients' reliance on self medication and pharmacy or drug shop attendance) that may delay seeking of appropriate medical care. The greater proportion of health service delay found in our study is similar to prior findings from studies in Ghana, Botswana and Gambia[7,9,10], but contrary to findings from South-Africa and Tanzania $[11,12]$. This long health service delay conceivably reflects insufficient knowledge of the signs and symptoms of TB among different types of health providers and the general population. The shorter patient delay found in our study, contrasts with findings of Oola (2001), in which patient delay was prolonged[5]. Most of the patients $(61.5 \%)$ in Oola's study were rural based, compared to the more urban setting of the present study. Rural residence has been found to be a risk factor for late diagnosis because of poorer access to health care and differences in education levels between rural and urban areas $[10,11]$.

\section{Factors associated with patient delay}

In this present study, perception of smoking as a cause of TB was associated with prolonged patient delay. This may be because cough appearing in smokers is often attributed to smoking, resulting in delays seeking help for TB related 
Table 4: Relationship between socio-demographic, lifestyle and health seeking factors to Health service delay. Both unadjusted and adjusted odds ratios are shown $(n=23 I)$

\begin{tabular}{|c|c|c|c|c|c|}
\hline Variable & $\mathbf{n}$ & $\begin{array}{l}\% \text { Health service delay } \\
>4 \text { weeks }\end{array}$ & $\begin{array}{l}\text { Unadjusted odds ratio } \\
\qquad(95 \% \mathrm{Cl})\end{array}$ & $\mathrm{n}^{*}$ & $\begin{array}{c}\text { Adjusted odds ratio } † \\
(95 \% \mathrm{Cl})\end{array}$ \\
\hline Age $18-40, y$ & 205 & 81.0 & $0.77(0.25-2.37)$ & & NA \\
\hline Male & 132 & 81.1 & $0.95(0.49-1.86)$ & & NA \\
\hline Hospitalised & 59 & 86.4 & $\mathrm{I} .63(0.7 \mathrm{I}-3.75)$ & & NA \\
\hline Marital status separated/single & 125 & 82.1 & $1.09(0.56-2.12)$ & & NA \\
\hline Post primary education level & 92 & 83.5 & $1.40(0.72-2.73)$ & & NA \\
\hline Single Household person & 24 & 66.7 & $0.41(0.16-1.03)$ & 23 & $0.31(0.11-0.84) \ddagger$ \\
\hline Daily Alcohol consumption & 38 & 85.7 & $1.44(0.53-3.97)$ & & NA \\
\hline Subsistence farming & 28 & 89.3 & $2.05(0.59-7.11)$ & & NA \\
\hline Perceived smoking as cause of TB & 34 & 87.5 & $1.62(0.20-13.56)$ & & NA \\
\hline$>2$ Health seeking encounters per month & 76 & 89.5 & $2.48(1.09-5.65)$ & 72 & $2.74(1.10-6.83) \ddagger$ \\
\hline $\begin{array}{l}\text { Medical expenditure on TB related } \\
\text { symptoms ( }>29 \text { US } \$)\end{array}$ & 60 & 88.3 & $2.02(0.85-4.82)$ & 60 & $3.88(1.19-12.62) \ddagger$ \\
\hline Hemoptysis at onset & 33 & 93.9 & $4.05(1.02-15.90)$ & & NA \\
\hline
\end{tabular}

*Number included in forward stepwise logistic regression method.

†Odds ratios for the variables appearing at the final step of forward stepwise selection.

$\ddagger \mathrm{P}<0.05 ; \mathrm{Cl}$ indicates confidence interval; NA not applicable.

symptoms. By contrast, in Philippines[13], there was no relationship between perceived causes of TB and healthseeking due to potential recall and selection biases. Education status had no effect on delay to treatment initiation as established elsewhere[10,11]. However subsistence farmers were found to have long patient delays probably due to lack of education and poverty. Similarly, alcoholics had prolonged patient delays. Gender had little impact on delay[14], though other studies have confirmed prolonged delays to initiation of treatment among females $[5,7,11]$. However larger studies should be undertaken to explore the effect of gender on access to health care. Severity of initial symptoms had no effect on delay possibly due to recall bias and individual variations in perception of disease.

\section{Factors associated with health service delay}

Our study revealed that the private health system is the common first choice of care for TB patients in Kampala district, with approximately $75 \%$ of individuals presenting to a private clinic, pharmacy or drug shop initially. In contrast, $75 \%$ of the patients in South Africa used the public health system as the initial contact[11]. This may be partly related to the health-care service quality. The public health sector in Uganda offers a free health service in agreement with the government health policy, though existing under-funding of this sector leads to insufficient utilities and consequently discourages it's optimal use. Longer delays to treatment were experienced among patients originating from peri-urban localities in which limited access to primary health care services significantly contributes to late diagnosis $[7,10]$.
Multiple health seeking encounters contributed to the prolonged duration of health service delay along with the associated medical costs. A low level of clinical suspicion of TB by health providers and failure to order proper investigations or refer patients to 'higher level' health units contributes in a major way to health service delay. Patients often need to return to the same providers of healthcare or seek advice from others, because of persistent symptoms $[6,15]$.

\section{Clinical features associated with delay to treatment}

Our study found that patients who required hospitalisation prior to TB diagnosis had shorter delays to treatment and less advanced disease, compared to out-patients. This shorter delay to treatment is partly explained by the finding that hospitalisation was HIV associated. In Ghana [7] hospitalised patients had more advanced disease and prolonged delays to treatment, though HIV status was not documented. A disparity in the HIV epidemic transitions in both countries is a possible explanation for this difference. The presence of limited cavitary disease among known HIV positive patients is known to be related to diminished immune function. Illness severity as measured by chest radiography and sputum smear grades was found to be associated with the duration of delay to treatment. Advanced disease has been found to correlate with mortality and chronic morbidity [7].

\section{Conclusion}

Patient and health service delays contribute significantly to delays in patients accessing treatment. Substantial reduction in case detection delays may be achieved 
through; 1) More specific and effective health education of the general public on tuberculosis and seeking of appropriate medical consultation; 2) Targeting specific groups of alcoholics and subsistence farmers to improve accessibility to TB treatment 3) Continuing medical education about TB management procedures for health providers; 4) Improvement in the capacity of TB control services. Similar research in the future could serve as a basis for monitoring improvement in the quality of the tuberculosis control program in Uganda.

\section{Competing interests}

The author(s) declare that they have no competing interests.

\section{Authors' contributions}

MSK conceived of the study, wrote the research proposal, conducted the research, did data entry, performed statistical analysis and wrote the manuscript. KC was involved in the write up of the proposal, data analysis and draft of the manuscript. MKH was involved in the write up of the proposal, data analysis and draft of the manuscript.

\section{Acknowledgements}

The authors wish to thank all the staff of the National Referral Tuberculosis treatment centre who participated in the study particularly Mr. Augustine Banyanga, Mr Okot Gabriel and the research assistants Dr. Henry Wamala and Dr. Helen Byakwaga. This study was supported by a WHO-TDR Grant.

\section{References}

I. Uganda MoH: National Tuberculosis and leprosy control Program Annual report. 2002.

2. Ministry of Health Uganda: Guidelines for National demonstration and Training Districts implementing DOTS, Ministry of Health NTLP Working draft Kampala. 1997.

3. World Health Organisation. Global tuberculosis control: WHO Report 2003. In WHO/CDS/TB/2003.3/6 Geneva, WHOM; 2003.

4. Ngamvithayapong J, Winkvist A, Diwan V: High AIDS awareness may cause tuberculosis patient delay: results from an HIV epidemic area, Thailand. AIDS 2000, I4(10):|4|3-14|9.

5. Oola J: Factors influencing Delayed diagnosis of tuberculosis in Mukono District Uganda. Institute of Public Health; $200 \mathrm{I}$.

6. Liam CK, Tang BG: Delay in the diagnosis and treatment of pulmonary tuberculosis in patients attending a university teaching hospital. Int J Tuberc Lung Dis I997, I(4):326-332.

7. Lawn SD, Afful B, Acheampong JW: Pulmonary tuberculosis: diagnostic delay in Ghanaian adults. Int J Tuberc Lung Dis 1998, 2(8):635-640.

8. Guwatudde D, Nakakeeto M, Jones-Lopez EC, Maganda A, Chiunda A, Mugerwa RD, Ellner J], Bukenya G, Whalen CC: Tuberculosis in household contacts of infectious cases in Kampala, Uganda. Am J Epidemiol 2003, I 58(9):887-898.

9. Steen TW, Mazonde GN: Pulmonary tuberculosis in Kweneng District, Botswana: delays in diagnosis in 212 smear-positive patients. Int J Tuberc Lung Dis 1998, 2(8):627-634.

10. Lienhardt C, Rowley J, Manneh K, Lahai G, Needham D, Milligan P, McAdam KP: Factors affecting time delay to treatment in a tuberculosis control programme in a sub-Saharan African country: the experience of The Gambia. Int J Tuberc Lung Dis 200I, 5(3):233-239.

II. Pronyk RM, Makhubele MB, Hargreaves JR, Tollman SM, Hausler HP: Assessing health seeking behaviour among tuberculosis patients in rural South Africa. Int J Tuberc Lung Dis 200I, 5(7):619-627.
12. Wandwalo ER, Morkve O: Delay in tuberculosis case-finding and treatment in Mwanza, Tanzania. Int J Tuberc Lung Dis 2000, 4(2): $133-138$.

13. Auer C, Sarol J Jr, Tanner M, Weiss M: Health seeking and perceived causes of tuberculosis among patients in Manila, Philippines. Trop Med Int Health 2000, 5(9):648-656.

14. Godfrey-Faussett $P$, Kaunda $H$, Kamanga J, van Beers S, van Cleeff M, Kumwenda-Phiri $R$, Tihont $V$ : Why do patients with a cough delay seeking care at Lusaka urban health centres? A health systems research approach. Int J Tuberc Lung Dis 2002, 6(9):796-805.

15. Needham DM, Foster SD, Tomlinson G, Godfrey-Faussett P: Socioeconomic, gender and health services factors affecting diagnostic delay for tuberculosis patients in urban Zambia. Trop Med Int Health 200I, 6(4):256-259.

\section{Pre-publication history}

The pre-publication history for this paper can be accessed here:

http://www.biomedcentral.com/1471-2458/5/122/pre pub

Publish with Biomed Central and every scientist can read your work free of charge

"BioMed Central will be the most significant development for disseminating the results of biomedical research in our lifetime. " Sir Paul Nurse, Cancer Research UK

Your research papers will be:

- available free of charge to the entire biomedical community

- peer reviewed and published immediately upon acceptance

- cited in PubMed and archived on PubMed Central

- yours - you keep the copyright

BiolMedcentral 